\title{
NONO Is a Negative Regulator of SOX2 Promoter
}

\author{
SHANSHAN LIANG ${ }^{1,2,3}$, HIDEHISA TAKAHASHI $^{4,5}$, TETSURO HIROSE $^{6}$, \\ YASUHIRO KURAMITSU ${ }^{7}$, SHIGETSUGU HATAKEYAMA ${ }^{4}$, HIRONORI YOSHIYAMA ${ }^{2}$, \\ RUOYU WANG ${ }^{1}$, JUN-ICHI HAMADA ${ }^{3,7}$ and HISASHI IIZASA ${ }^{2,3}$ \\ ${ }^{1}$ The Key Laboratory of Biomarker High-throughput Screening and Target \\ Translation of Breast and Gastrointestinal Tumor, Oncology Department, \\ Affiliated Zhongshan Hospital of Dalian University, Dalian, P.R. China; \\ ${ }^{2}$ Department of Microbiology, Faculty of Medicine, Shimane University, Shimane, Japan; \\ ${ }^{3}$ Division of Stem Cell Biology, Institute for Genetic Medicine, Hokkaido University, Hokkaido, Japan; \\ ${ }^{4}$ Department of Biochemistry, Hokkaido University Graduate School of Medicine, Sapporo, Japan; \\ ${ }^{5}$ Department of Molecular Biology, Yokohama City University School of Medicine, \\ Yokohama City University Graduate School of Medical Science, Yokohama, Japan; \\ ${ }^{6}$ Division of RNA Bio-function, Institute for Genetic Medicine, Hokkaido University, Sapporo, Japan; \\ ${ }^{7}$ Health Science University of Hokkaido School of Nursing \& Social Services, Hokkaido, Japan
}

\begin{abstract}
Background/Aim: Sex determining region Y (SRY)box 2 (SOX2) is a transcription factor essential for the maintenance of proliferation and self-renewal of cancer stem cells and is associated with breast cancer initiation. Regulation of cancer stem cell plasticity by SOX2 requires both positive and negative SOX2 transcription factors, but the negative regulator is still largely unknown. Materials and Methods: SOX2 promoter-binding proteins were identified by liquid chromatography-mass spectrometry/mass spectrometry, luciferase assay, and chromatin immunoprecipitation. The effects of one such transcription factor on SOX2 expression was investigated by knockdown and overexpression experiments. Results: Non-POU domain-containing octamerbinding protein (NONO) (also known as 54-kDa nuclear RNA-binding protein, P54NRB) was identified as a SOX2 promoter-binding protein and a negative regulator of SOX2 expression. Its activity was controlled by its coiled-coil domain and the C-terminal domain. Conclusion: These results suggest that NONO acts as a key regulator of SOX2 transcription through the repression of SOX2 promoter activity in breast cancer cells.
\end{abstract}

This article is freely accessible online.

Correspondence to: Jun-ichi Hamada,1757 Kanazawa, Tobetsu-cho, Ishikari-gun, Hokkaido 061-0293, Japan. E-mail: jun1hamada@hokuiryo-u.ac.jp and Hisashi Iizasa, 89-1 Enya, Izumo, Shimane 6398501, Japan. E-mail: iizasah@med.shimane-u.ac.jp

Key Words: SOX2, negative regulator, transcription factor, breast cancer, cancer stem cell.
Sex-determining region Y-box 2 (SOX2) is a transcription factor that is associated with tumor malignancy of glioma cells, ovarian cancer, head and neck cancer, and breast cancer (1). In breast cancer, the expression level of SOX2 is associated with tumor size and the number of metastatic lymph nodes (2). SOX2 overexpression also enhances tumorinitiating activity in breast cancer cell lines (3). These reports suggest that SOX2 is an important factor for maintenance of cancer stem cells (CSCs).

Recently, it was pointed out that CSCs have plasticity and may reversibly change their behavior between non-CSCs and CSCs (4). Therefore, if the properties of CSCs are controlled by SOX2, SOX2 expression must not only be induced but also suppressed. In many cancer types, SOX2 mRNA expression is mainly controlled by its promoter $(5,6)$, and nuclear transcription factor $\mathrm{Y}$ subunit alpha, transcription adaptor putative zinc finger, and glioma associated oncogene family zinc finger 1 have been reported as enhancers of the SOX2 promoter (7-9). However, the negative regulators of SOX2 transcriptional are largely unknown in breast cancer.

While non-pituitary-specific factor, octamer transcription factor, neural un-coordinated-86 (POU) domain-containing octamer-binding protein (NONO; previously known as 54$\mathrm{kDa}$ nuclear RNA-binding protein/P54NRB) is an RNA splicing factor, it also binds to DNA using a POU-like element and regulates transcription through a coiled-coil domain (10). NONO interacts with SOX9 and induces transcription of collagen, type II, alpha 1 gene, which is a differentiation marker of chondrocytes, by binding to the promoter (11). NONO also induces transcription of sterol regulatory element-binding protein-1a in breast cancer (12). On the other hand, NONO acts as a transcriptional repressor 
for the connexin 43 gene (13) and cyclooxygenase-2 (COX2) (14). Characteristically, NONO is highly expressed in estrogenreceptor-positive breast cancer (15) but pathophysiological roles of NONO in human breast cancer are largely unknown. In this study, we investigated the molecular mechanisms regulating SOX2 expression in breast cancer cell lines.

\section{Materials and Methods}

Cell lines. Human breast cancer cell lines, MCF-7 and T-47D were obtained from American Type Culture Collection (Manassas, VA, USA). These cell lines were cultured in Dulbecco's modified Eagle medium/Ham's Nutrient Mixture F-12 (DMEM/F-12) (Wako Pure Chemical, Osaka, Japan) supplemented with heat-inactivated $10 \%$ fetal bovine serum (Cambrex, East Rutherford, NJ, USA), 100 units $/ \mathrm{ml}$ penicillin and $100 \mu \mathrm{g} / \mathrm{ml}$ streptomycin sulfate (both from Invitrogen, Carlsbad, CA, USA), and maintained at $37^{\circ} \mathrm{C}$ with $5 \% \mathrm{CO}_{2}$.

Identification of the region essential for transcriptional activity in the SOX 2 promoter. To identify SOX 2 promoter essential region, luciferase assay was used. The human SOX2 promoter region was amplified from genomic DNA of MCF-7 cells (5). It was amplified using KOD-Plus-Neo DNA polymerase with proof reading activity (TOYOBO, Osaka, Japan) and $0.3 \mu \mathrm{M}$ of specific primers. The sequences of the primers used were: P789 forward: 5'-GGTACCGGCCAAAGAGCTGAGTTGG-3', P629 forward: 5'-GGTACCAACTTCTAGTCGGGACTGTG-3', P467 forward: 5'-GGTACCCTGGCTGTTTCCAGAAATAC-3', P227 forward: 5'-GGTACCCTCAGTGGCTGGCAGGC-3', P68 forward: 5'-GGTACCGCTGATTGGTCGCTAGAAAC-3'; reverse: 5'AAGCTTGAGGCAAACTGGAATCAGGATC-3'). Thermal cycling procedure consisted of an initial denaturation for $2 \mathrm{~min}$ at $94^{\circ} \mathrm{C}$. This was followed by 30 cycles of denaturation at $98^{\circ} \mathrm{C}$ for 10 $\mathrm{s}$, annealing at $55-58^{\circ} \mathrm{C}$ for $30 \mathrm{~s}$ and extension at $68^{\circ} \mathrm{C}$ for $30 \mathrm{~s}$. ATailing was then carried out by incubating $5.9 \mu \mathrm{l}$ of the polymerase chain reaction (PCR) products with $1 \mu \mathrm{l}$ of GoTaq polymerase (Promega, Madison, WI, USA), $2 \mu \mathrm{l}$ of $5 \times$ Go Taq reaction buffer, $0.6 \mu \mathrm{l}$ of $2.5 \mathrm{mM} \mathrm{MgCl}_{2}$, and $0.5 \mu \mathrm{l}$ of $4 \mathrm{mM}$ dATP for $30 \mathrm{~min}$ at $70^{\circ} \mathrm{C}$. The A-tailed PCR products were then ligated into pGEM-T easy vectors (Promega), which were further digested with KpnI and HindIII (TAKARA Bio, Shiga, Japan) enzymes. Fragments obtained from the restriction digestion were inserted into pGL3-Basic luciferase vector (Promega). An electroporator was used to cotransfect $1 \mu \mathrm{g}$ of generated vectors and $25 \mathrm{ng}$ of the internal control, pRL-TK vector (Promega) into $5 \times 10^{5}$ cells with or without $0.5 \mu \mathrm{g}$ of complementary DNA (cDNA) expression vectors (CUY21SC; NepaGene, Ichikawa, Japan). Transfected cells were seeded into one well. Forty-eight hours after transfection, luciferase activity was measured using the Dual-Luciferase Reporter Assay System (Promega) with a luminometer MiniLumat (Berthold, Bad Wildbad, Germany). The results were normalized by dividing the luciferase reporter activity by that of the Renilla reporter, which were then statistically compared among the groups using Mann-Whitney $U$-test.

Biotin-streptavidin pulldown assay. To isolate SOX2 promoter activity regulatory factors, biotin-streptavidin pulldown assay was performed. Nuclear fractions $(100 \mu \mathrm{l})$ were prepared from $2 \times 10^{6} \mathrm{MCF}-7$ cells using NE-PER Nuclear and Cytoplasmic Extraction Reagent following the manufacturer's instructions (Thermo Fisher Scientific, Pittsburg, PA,
USA). Subsequently, $100 \mu \mathrm{l}$ of the nuclear fraction was incubated with $17 \mu \mathrm{l}$ of Streptavidin Mag Sepharose (GE Healthcare Bioscience, Pittsburgh, PA, USA) at $4^{\circ} \mathrm{C}$ for $2 \mathrm{~h}$ in $1 \mathrm{ml}$ of binding buffer [ $20 \%$ glycerol, $20 \mathrm{mM}$ Tris pH 7.5, $100 \mathrm{mM} \mathrm{KCl}, 1 \mathrm{mM}$ dithiothreitol (DTT), $20 \mu \mathrm{g} / \mathrm{ml}$ bovine serum albumin (BSA), $2 \mathrm{mM}$ EDTA] on a shaking incubator. After incubation, the mixtures were centrifuged at 5,000 $\times g$ for $1 \mathrm{~min}$ at $4^{\circ} \mathrm{C}$. Supernatants were transferred to a fresh tube as the nuclear fractions were removed by avidin binding protein. Mag Sepharose-bound complex was washed twice with $100 \mu$ of binding buffer without BSA and washed buffers were stored at $-80^{\circ} \mathrm{C}$. Human SOX2 promoter-derived $\mathrm{P} 227$ and $\mathrm{P} 68$ regions were then amplified from MCF-7 genomic DNA using KOD Plus-Neo with biotin-labeled primers for P227 (forward, 5'-biotin-CTCAGTGGCTGGCAGGCTGG-3'), P68 (forward: 5'-biotin-GCTGATTGGTCGCTAGAAACC-3'), and reverse: 5'-GAGGCAAACTGGAATCAGGATC-3'. The nuclear fractions bound to avidin binding protein were incubated with $50 \mu \mathrm{l}$ of the biotinlabeled PCR products at $22^{\circ} \mathrm{C}$ for $4 \mathrm{~h}$. The biotin-labeled DNA-nuclear protein complex was incubated with $17 \mu$ of Streptavidin Mag Sepharose at $4^{\circ} \mathrm{C}$ for 1 hour and washed twice before it was resuspended in Laemmli sample buffer with $5 \%$ (v/v) $\beta$-mercaptoethanol. To break the streptavidin-biotin interaction, $20 \mu \mathrm{l}$ of the re-suspended protein complex was heated at $98^{\circ} \mathrm{C}$ before it was separated on MiniPROTEAN ${ }^{\circledR}$ TGX $^{\text {TM }}$ Precast Gels (BIO-RAD, Hercules, CA, USA). Sodium dodecyl sulfate polyacrylamide gel electrophoresis (SDSPAGE) gels were then stained using SilverQuest ${ }^{\mathrm{TM}}$ Silver Staining Kit (Invitrogen), and specific bands were analyzed by liquid chromatography-mass spectrometry/mass spectrometry (LC-MS/MS) analysis.

In-gel digestion. To purify SOX2 promoter-binding proteins from SDS-PAGE, in-gel digestion was performed. The SDS-PAGE gel was rinsed twice with $15 \mathrm{mM}$ potassium ferricyanide and $50 \mathrm{mM}$ sodium thiosulfate solution for $15 \mathrm{~min}$ to destain it. The gel was then rinsed twice with ultrapure water and the sample in the gel piece was reduced twice in a solution containing 50\% acetonitrile (ACN), $50 \mathrm{mM}$ ammonium bicarbonate, and $5 \mathrm{mM}$ DTT for $10 \mathrm{~min}$. The gel piece was dehydrated in $100 \%$ ACN twice for 30 min each, and then rehydrated with an in-gel digestion reagent containing 10 $\mu \mathrm{g} / \mathrm{ml}$ Sequencing-Grade Modified Trypsin (Promega) in 30\% ACN, $50 \mathrm{mM}$ ammonium bicarbonate, and $5 \mathrm{mM}$ DTT. This procedure for in-gel digestion was performed overnight at $30^{\circ} \mathrm{C}$. After digestion, the samples were lyophilized overnight using Labconco Lyph-Lock 1L Model 77400 (Labconco, Kansas, MO, USA). Lyophilized samples were then dissolved in $0.1 \%$ formic acid.

LC-MS/MS analysis. To identify SOX2 promoter-binding proteins, LCMS/MS analysis was performed. Twenty-five microliters of each sample were separated on a Zorbax 300SB-C18 column $(75 \mu \mathrm{m} \times 150$ mm; Agilent Technologies, Palo Alto, CA, USA). The capillary pump of Agilent 1100 LC/MSD Trap XCT (Agilent Technologies) was operated under the following conditions: solvent A: $0.1 \%$ formic acid, solvent $\mathrm{B}$ : $\mathrm{ACN}$ in $0.1 \%$ formic acid; column flow: $0.3 \mu \mathrm{l} / \mathrm{min}$, primary flow: $300 \mu \mathrm{l} / \mathrm{min}$; gradient: $0-5 \mathrm{~min} 2 \%$ solvent $\mathrm{B}, 60 \mathrm{~min} 60 \%$ solvent $\mathrm{B}$; stop time: $60 \mathrm{~min}$. Protein identification was performed in the Agilent Spectrum Mill MS proteomics workbench against the SwissProt protein database search engine (http://kr.expasy.org/sprot/) and the MASCOT MS/MS Ions Search engine (http://www.matrixscience.com/ search_form_select.html). The criteria for positive identification of proteins were set as follows: filter by protein score $>10.0$, and filter peptide by score $>8, \%$ scored peak intensity. 
Quantitative reverse transcription-PCR ( $q R T-P C R$ ). To analyze SOX2 mRNA expression, qRT-PCR was performed on ABI Prism 7900HT (Applied Biosystems, Grand Island, NY, USA) using $2 \times$ QuantiFast SYBR Green PCR Master Mix (Qiagen, Valencia, CA, USA) with $0.5 \mu \mathrm{M}$ primers. Specific primer sets used were as follows: human SOX2 forward: 5'-TGGACAGTTACGCGCACAT-3', reverse: 5'-CGAGTAGGACATGCTGTAGGT-3'; and $\beta$-Actin forward: 5'TTGCCGACAGGATGCAGAA-3' and reverse: 5' GCCGATCCACACGGAGTACT-3'. The gene expression of SOX2 and the endogenous control, $\beta$-Actin were analyzed in three independent qRT-PCR assays. The thermal cycling procedure included an initial denaturation step for $5 \mathrm{~min}$ at $95^{\circ} \mathrm{C}$, followed by 40 cycles of $95^{\circ} \mathrm{C}$ for $10 \mathrm{~s}$ and $60^{\circ} \mathrm{C}$ for $30 \mathrm{~s}$. Relative expression of the target gene was analyzed by the $\Delta \Delta \mathrm{Ct}$ method. Ratios of mRNA levels were expressed relative to those of the control group.

$R N A$ repression by small-interfering RNA (siRNA). To repress NONO mRNA expression, $N O N O$-specific siRNA was treated to MCF-7 or T-47D cells. BLOCK-iT RNAi Designer (Invitrogen) was used to design siRNAs with the following sequences were as follows: NONO sense, 5'-GCAUUCCUGAAGUCUCUAATT-3'; antisense, 5'UUAGAGACUUCAGGAAUGCTT-3'. AllStars Negative Control siRNA (Qiagen) was used as a negative control. Trypsinized MCF7 cells $\left(1 \times 10^{6}\right.$ cells $)$ were re-suspended in $100 \mu$ of Opti-Minimal Essential Medium (Invitrogen) followed by the addition of the siRNA such that the final concentration was $4 \mu \mathrm{M}$. Transfections were performed in an electroporation cuvette using a CUY21SC electroporator (NepaGene). The transfected cells were transferred to DMEM/F-12 containing $10 \%$ fetal bovine serum, incubated for $48 \mathrm{~h}$ in a humidified incubator maintained at $37^{\circ} \mathrm{C}$ and $5 \% \mathrm{CO}_{2}$. After 48 $\mathrm{h}$, the cells were harvested for RNA or protein preparation.

Chromatin immunoprecipitation (ChIP) assay. To confirm NONO binding on SOX2 promoter, ChiP assay was performed using antiNONO antibody and qPCR for SOX2 promoter region. Cells were seeded in 10-cm dishes and were harvested when it reached $80 \%$ confluency. Cross-linking was performed by incubating the cells in 500 $\mu \mathrm{l}$ of $1 \%$ formaldehyde prepared in phosphate-buffered saline (PBS) for $20 \mathrm{~min}$ at $20^{\circ} \mathrm{C}$. After incubation, the cells were washed twice in icecold PBS, and lysed in $100 \mu \mathrm{l}$ of ChIP lysis buffer (0.5\% SDS, $50 \mathrm{mM}$ Tris- $\mathrm{HCl} \mathrm{pH} 8.0,150 \mathrm{mM} \mathrm{NaCl}, 10 \mathrm{mM}$ EDTA) for $30 \mathrm{~min}$ at $20^{\circ} \mathrm{C}$ The cells lysates were then sonicated for $30 \times 30 \mathrm{~s}$ at the maximum power setting on a Bioruptor Sonicator (Diagenode, Denville, NJ, USA) to generate DNA fragments of 150-500 bp in length. Sonicated samples were then centrifuged at $19,000 \times g$ for $10 \mathrm{~min}$ at $4^{\circ} \mathrm{C}$, and the supernatant was pre-cleared by incubating in $50 \%$ protein $\mathrm{G}$ agarose slurry (GE Healthcare) prepared in BSA/PBS for $2 \mathrm{~h}$ at $4^{\circ} \mathrm{C}$. Pre-cleared samples were then incubated at $4^{\circ} \mathrm{C}$ overnight with $10 \mu \mathrm{g}$ of normal mouse IgG (sc-2025, Santa Cruz Biotechnology, Dallas, TX, USA), antiPOL2 antibody (F-12, Santa Cruz Biotechnology), anti-NONO antibody (clone 3/p54nrb (RUO), BD Bioscience, Franklin Lakes, NJ, USA). The following day, $20 \mu \mathrm{l}$ of protein $\mathrm{G}$ agarose was added and incubated with rotation for $2 \mathrm{~h}$ at $4^{\circ} \mathrm{C}$, followed by a series of washes: twice with IP buffer (20 mM Tris-HCl pH 8.0, $150 \mathrm{mM} \mathrm{NaCl}, 2 \mathrm{mM}$ EDTA, and $1 \%$ Triton X-100), twice with high-salt buffer (20 mM Tris-HCl pH 8.0, 500 $\mathrm{mM} \mathrm{NaCl}, 2 \mathrm{mM}$ EDTA, and $1 \%$ Triton X-100), once with LiCl buffer (250 mM LiCl, 20 mM Tris-HCl pH 8.0, 1 mM EDTA, 1\% Triton X$100,0.1 \%$ NP40, and $0.5 \%$ sodium deoxycholate), and twice with 10 $\mathrm{mM}$ Tris -1 mM EDTA ( $\mathrm{pH}$ 8.0) buffer. Samples were eluted from the beads with $0.1 \mathrm{M} \mathrm{Na}_{2} \mathrm{CO}_{3}$ and $1 \%$ SDS by heating the mixture at $67^{\circ} \mathrm{C}$ for 30 min with intermittent vortexing at 10-min intervals. Samples were reverse-crosslinked overnight at $65^{\circ} \mathrm{C}$. Immunoprecipitated DNA and input DNA were incubated with RNase A and Proteinase K (Sigma, St Louis, MO, USA) at $45{ }^{\circ} \mathrm{C}$ for $2 \mathrm{~h}$. DNA was purified using QIAquick PCR Purification Kit (Qiagen) and then analyzed using qPCR. Primer sequences were as follows: SOX2 promoter -47 to -123 , forward: 5 'CCTTTCATGCAAAACCCG-3', reverse: 5'-GGGTTTCTAGCGA CCAATCA-3', and SOX2 promoter -69 to +58 , forward: 5'CGCTGATTGGTCGCTAGAAAC-3', reverse: 5'-CCCCTTTTGC AAACACTCTC-3'. qPCR was performed on an ABI Prism 7900HT using previously described protocol for qRT-PCR. The relative gene expression was analyzed using $\Delta \Delta \mathrm{Ct}$ method and compared with normal mouse IgG.

Western blotting. To analyze protein expression level of NONO or SOX2, western blotting was performed. pcDNA3-NONO-1xFLAG $(16,17)$ or pCMV-3XFLAG (Mock, provided by Dr. Koji Nakagawa, Health Science University of Hokkaido School of Nursing \& Social Services) were transfected into the cells by electroporation. Cells $\left(1 \times 10^{6}\right)$ were lysed using $100 \mu$ of RIPA buffer $(25 \mathrm{mM}$ Tris- $\mathrm{HCl} \mathrm{pH}$ 7.6, $150 \mathrm{mM} \mathrm{NaCl}, 1 \% \mathrm{NP}-40,1 \%$ sodium deoxycholate, and $0.1 \%$ SDS). Samples containing $20 \mu \mathrm{g}$ of protein extracts were separated on a $14 \%$ polyacrylamide gels and transferred onto PVDF membranes (Immobilon P; Millipore, Billerica, MA, USA). Antibodies against SOX2 (D6D9, Cell Signaling Technology, Danvers, MA, USA), NONO (clone 3/p54nrb (RUO), FLAG (M2: Sigma), $\beta$-Actin (clone C4: Millipore), anti-mouse $\operatorname{IgG}$ secondary antibodies, horseradish peroxidase (HRP)-linked $F(a b$ ')2 fragment sheep or anti-rabbit IgG, and HRP-linked F(ab')2 fragment donkey (GE Healthcare Bioscience) were used. Each protein band was detected using Western Chemiluminescent HRP Substrate (Immobilon, Millipore) and visualized by LAS1000mini (FUJIFILM Corp, Tokyo, Japan).

Immunocytochemistry. To analyze protein expression and localization of NONO or -SOX2, immunohistochemistry was performed using anti-NONO antibody or SOX2 antibodies. MCF-7 cells were seeded on glass-based 24 -well plates and fixed in $4 \%$ paraformaldehyde and $0.1 \%$ Triton $\mathrm{X}-100$ at $20{ }^{\circ} \mathrm{C}$ for 30 min after they reached $80 \%$ confluence. They were washed twice with $1 \times$ PBS for 5 min each and incubated with two primary antibodies, anti-SOX2 (D6D9) and antiNONO (clone 3/p54nrb; RUO). The cells were then incubated with biotinylated sheep anti-rabbit IgG or Alexa 568 conjugated goat antimouse $\operatorname{IgG}$ (Invitrogen), and avidin-conjugated Alexa 488 (Invitrogen). All the antibodies were diluted in $1 \times$ PBS pIus 3\% BSA. 4,6-Diamidino-2-phenylindole $(0.1 \mu \mathrm{g} / \mathrm{ml})$ was used for nuclear staining in order to confirm cellular localization of NONO and SOX2.

Generation of POU binding element mutated promoter vector. To analyze the effect of mutation of POU binding element in luciferase vector, plasmid vectors were constructed. P227-pGEM T vector was used as a template for PCR. The DNA fragment was amplified by KOD-Plus-Neo using $0.3 \mu \mathrm{M}$ of specific primers (P227 forward: 5'GGTACCCTCAGTGGCTGGCAGGC-3', POU-M reverse: 5'GGGTGGGTACAGCCCTGGGGCGGGGCCT-3', POU-M forward: 5'-AGGCCCCGCCCCAGGGCTGTACCCACCC-3', reverse 5'AAGCTTGAGGCAAACTGGAATCAGGATC-3') Mutated POU binding element is underlined in the above primer sequences. PCR products were extracted from agarose gel using QIAEXII (Qiagen), which served as templates for the second round of PCR using P227 forward and reverse primers. Thermal cycling procedure involved an initial denaturation step for $2 \mathrm{~min}$ at $94^{\circ} \mathrm{C}$, followed by 20 cycles of $98^{\circ} \mathrm{C}$ for $10 \mathrm{~s}, 58^{\circ} \mathrm{C} 30 \mathrm{~s}$, and $68^{\circ} \mathrm{C}$ for $30 \mathrm{~s}$. A-tailing of the PCR 
products was carried out, after which, they were ligated into pGEM$\mathrm{T}$ vector. The pGEM-T was then digested with restriction enzymes, Kpn I and Hind III. The fragment obtained was ligated to pGL3-Basic luciferase vector. The reporter vector with mutation in the POU binding element was designated as P227-M.

Generation of NONO deletion mutants. To confirm SOX2 binding elements in NONO protein, plasmid vectors were constructed. pcDNA3-NONO-1xFLAG was used as a template for PCR. DNA fragment was amplified by KOD-Plus-Neo using $0.3 \mu \mathrm{M}$ of specific primers ( $\Delta \mathrm{N}$ forward: 5'-AGCCGTCTTTTTGTGGGAAATC-3', reverse: 5'-CATGGTTCTATCTCCTTCGAAG-3', $\triangle \mathrm{R}$ forward: 5'TTAGATGATGAAGAGGGACT T-3', reverse: 5'-TCGTTGGGTG AAGGTCTTC-3', $\triangle$ CC forward: 5'-ACCTTCCCTGATGCGAGAG3', reverse: 5'-ATATTCATACTCAAAGGAGC-3', $\triangle \mathrm{C}$ forward: 5'TATGACCCAGCCTTTCTTGTAC-3', reverse: 5'-TCCCTT GAATCCTTCCTGCTG-3'). Thermal cycling included an initial denaturation step for $2 \mathrm{~min}$ at $94^{\circ} \mathrm{C}$, followed by 30 cycles at $98^{\circ} \mathrm{C}$ for $10 \mathrm{~s}, 58^{\circ} \mathrm{C}$ for $30 \mathrm{~s}$, and $68^{\circ} \mathrm{C}$ for $3 \mathrm{~min}$. PCR amplicons were digested with Dpn I. Digested PCR products were incubated with T4 polynucleotide kinase (New England Biolabs, Ipswich, MA, USA) for $30 \mathrm{~min}$ at $37^{\circ} \mathrm{C}$, followed by overnight incubation with T4 DNA ligase (Promega) at $16^{\circ} \mathrm{C}$. NONO coding regions of constructed vectors were sequenced, and expression of mutated NONO was confirmed by western blotting using FLAG antibody (M2: Sigma).

Flow cytometric (FACS) analysis. To confirm the SOX2-positive cell population in NONO siRNA-treated MCF-7 cells, FACS analysis was performed using antibody to SOX2. MCF-7 cells were fixed with $4 \%$ formaldehyde for $10 \mathrm{~min}$ at $37^{\circ} \mathrm{C}$ and permeabilized in ice-cold $100 \%$ methanol for $30 \mathrm{~min}$. The cells were then treated with $3 \%$ BSA for 1 $\mathrm{h}$ and incubated with anti-SOX2 (D6D9) for $1 \mathrm{~h}$ at $20{ }^{\circ} \mathrm{C}$. After washing with PBS, the cells were incubated with CF488A-conjugated goat anti-rabbit IgG antibody (Biotium, Hayward, CA, USA) for $1 \mathrm{~h}$ at $20^{\circ} \mathrm{C}$. Immunostained cells were analyzed by FACSAria III flow cytometer I (BD Biosciences, San Jose, CA, USA).

Sphere formation. To analyze cancer stemness in cells with repression of NONO expression, sphere formation assay was used. Control and NONO-specific siRNA transfected MCF-7 cells were seeded at 3,000/well on ultra-low-attachment 96-well plate (Sumitomo Bakelite Co., LTD, Tokyo, Japan) using FACSAria III and cultured in a sphere-formation medium (DMEM/F-12 supplemented with $20 \mathrm{ng} / \mathrm{ml}$ of epidermal growth factor, $20 \mathrm{ng} / \mathrm{ml}$ of basic fibroblast growth factor, $100 \mathrm{units} / \mathrm{ml}$ penicillin, and $100 \mu \mathrm{g} / \mathrm{ml}$ of streptomycin sulfate) for 7 10 days. Spheres formed were detected and counted under microscopic observation (IX73; Olympus, Tokyo, Japan).

Statistical analysis. Statistical analysis was performed to analyze whether or not there were any significant differences in the experimental results. Experiments were performed in triplicate or quadruplicate and conducted in a minimum of three independent trials. Data are presented as means \pm standard deviations. Two-tailed $t$-tests were conducted in which the acceptable level of significance was $p<0.05$.

\section{Results}

To determine the transcriptional regulatory region of human SOX2 promoter $(-789$ to +253$)$, deletion mutants were constructed. SOX2 promoter activity was reduced in all deletion mutants, with -629 to -467 containing the SOXbinding site, and -227 to -68 containing two $\mathrm{Sp} 1$ and one POU binding sites in breast cancer cell MCF-7 (Figure 1A). The SOX2 promoter -227 to -68 has $\mathrm{CpG}$ island and a highly conserved Sp1- and POU-binding elements (Figure 1B). To identify SOX2 promoter-binding proteins, biotin-labeled promoter core region and MCF-7-derived nuclear fraction were used (Figure 1C). By LC-MS/MS analysis, NONO, eukaryotic translation elongation factor $1 \alpha 2$ (eEF1 12 ), and heterogeneous nuclear RNA binding protein-A1 (hnRNPA1) were identified as promoter-binding proteins (Figure 1C).

To confirm the effect of $S O X 2$ promoter-binding proteins, promoter activity was examined with forced expression and knockdown experiments for these genes. Overexpression of NONO repressed P227 promoter activity compared with mock transfectant, but not that of P68 (Figure 2A). In addition, siRNA for $N O N O$ gene enhanced $\mathrm{P} 227$ promoter activity but not that of P68 (Figure 2B). The effect of NONO on P227 promoter was dependent on POU-like element (Figure 2C). Using ChIP assay, binding of NONO to SOX2 promoter at -227 to -69 was confirmed but not at -68 to +253 (Figure 2D). In addition, siRNA for NONO enhanced RNA polymerase II recruitment to $S O X 2$ promoter (Figure 2E). $S O X 2$ promoter activities were not affected by eEF1 $\alpha 2$ and hnRNPA1 (data not shown). These results indicate that NONO acts as a negative regulator for $\mathrm{SOX} 2$ promoter.

NONO has several domain structures, such as RNAbinding domain and coiled-coil domain (18). To confirm SOX2 promoter regulatory domains in NONO, deletion mutants were constructed (Figure 3A). Deletion mutants of the coiled-coil domain and $C$-terminal region did not repress the activity of full length $S O X 2$ promoter $(-789$ to +253$)$ nor partial SOX2 promoter $(-227$ to +253$)$ (Figure 3B). This indicates that NONO represses $S O X 2$ promoter activities by coiled-coil domain and $C$-terminal region.

To confirm the role of NONO in SOX2 expression, NONO overexpression and knockdown experiments were performed. Overexpression of $N O N O$ reduced $\mathrm{SOX} 2$ protein expression (Figure 4A) while siRNA for $N O N O$ gene enhanced SOX2 protein expression (Figure 4B). siRNA for $N O N O$ induced SOX2 mRNA expression in breast cancer cell line MCF-7 and T-47D (Figure 4C) compared with siRNA control transfectant. siRNA for $N O N O$ enhanced the percentage of the SOX2-positive population in MCF-7 cells (Figure 4D). NONO was ubiquitously expressed in the nucleus and SOX2 was also expressed in the nucleus (Figure 4E). However, the expression of NONO was negatively correlated with that of SOX2, and NONO-positive, SOX2-negative cells existed in MCF-7 (Figure 4E, white arrow). It has been reported that SOX2 expression is associated with sphere-forming activity (3). NONO knockdown enhanced sphere formation of MCF7 cells (Figure 4F). These results indicate that NONO is a repressor of SOX2 expression in breast cancer cell lines. 


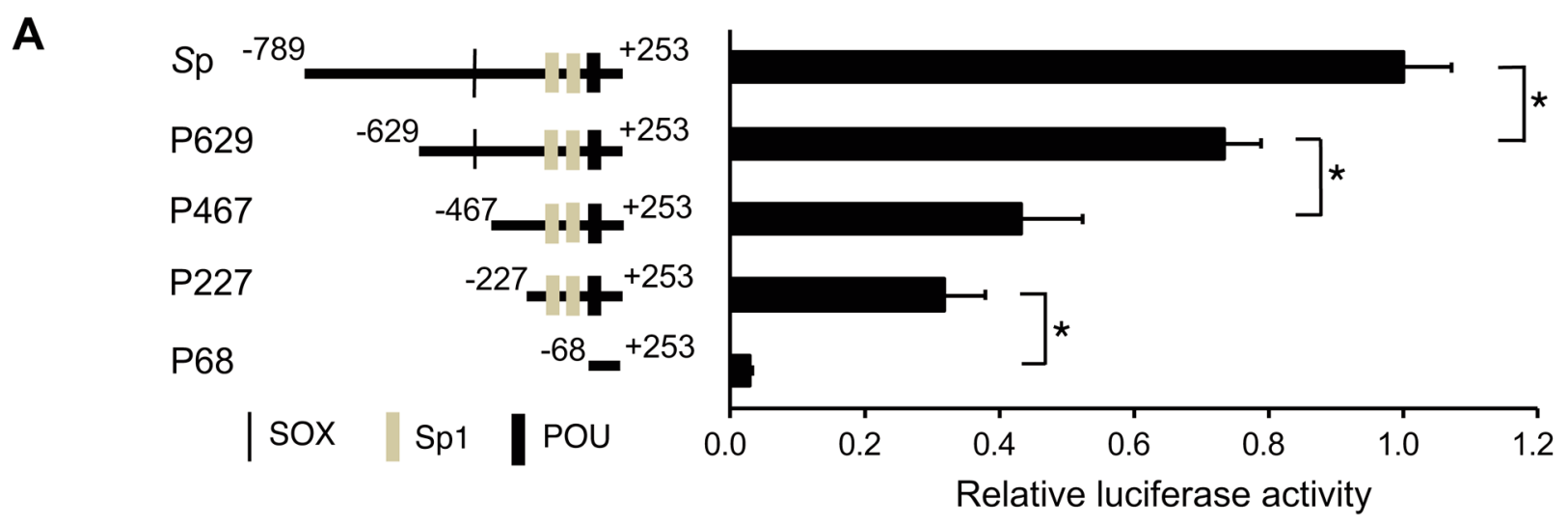

B

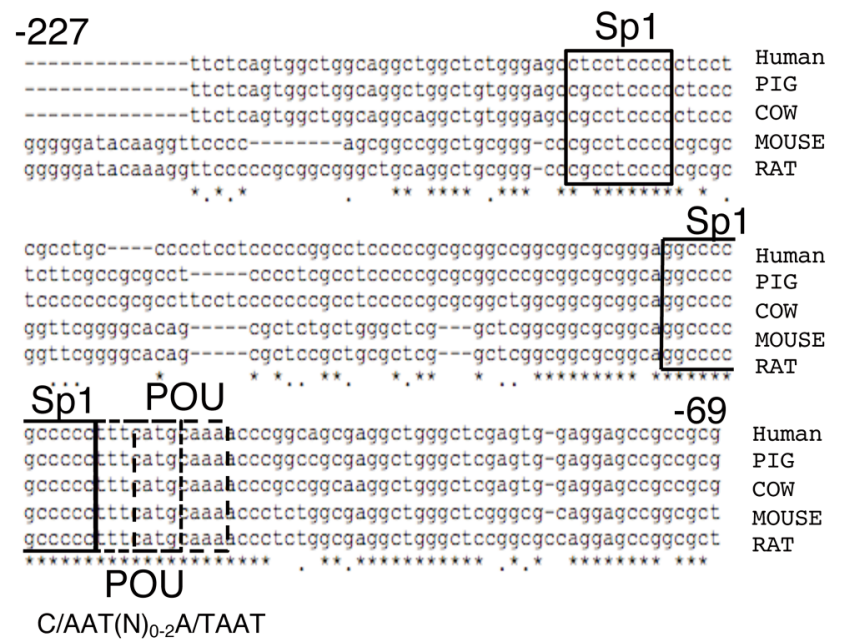

C Biotin-labeled

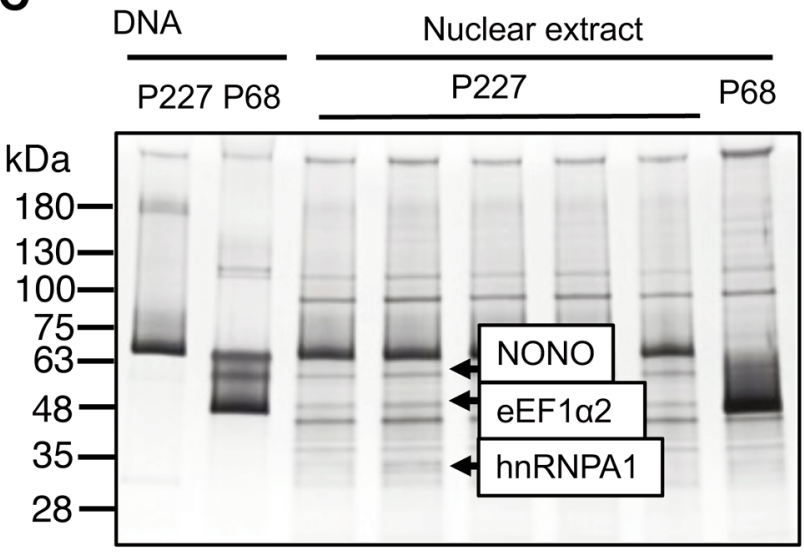

Figure 1. Identification of human sex-determining region Y-box 2 (SOX2) promoter-binding proteins in MCF-7 cells. A: SOX2 promoter deletion mutant activity in breast cancer cell lines. Light black bar: SOX-binding element, gray bar: Sp1-binding element, heavy black bar: pituitary-specific factor, octamer transcription factor, neural un-coordinated-86 (POU) l like-binding element, Sp: SOX2 promoter (-789 to +253). Renilla luciferase activity was used as an internal control. All promoter activities are shown relative to that of Sp promoter activity. B: Putative SOX 2 promoterbinding factors and their binding elements in the region at positions -227 to +253 . C: Identification of SOX 2 promoter-binding proteins from nuclear extract of MCF-7 cells in the region at positions -227 to -69 . NONO: non-POU domain-containing octamer-binding protein; eEF1 $\alpha 2$ : eukaryotic translation elongation factor $1 \alpha 2 ;$ hnRNPA1: heterogeneous nuclear RNA binding protein-A1. *Significantly different at p<0.05.

\section{Discussion}

In this study, we identified NONO as a SOX2 promoterregulatory factor in human breast cancer cell lines. NONO regulated SOX2 promoter activity using the $C$-terminal region and coiled-coil domain, which were previously reported as a POU element-binding region (19). NONO has high homology with family gene splicing factor, proline- and glutamine-rich (SFPQ) and paraspeckle component 1 (PSPC1) in RNA binding domains (18). The complex of SFPQ and NONO binds retinoid $\mathrm{X}$ receptor and represses transcription using histone deacetylase recruitment (20). However, SFPQ and PSPC1 overexpression did not alter SOX2 protein expression (data not shown). This is consistent with the low homology between the $C$-terminal regions of these two proteins and NONO.

Two patterns are known for transcriptional regulation by NONO $(14,21,22)$. One is where a complex with a hormone receptor is formed to recognize a hormone receptor-binding sequence and to regulate transcription $(21,22)$. The other is where NONO directly binds to the POU element and regulates transcription, as seen in the transcriptional regulation of the COX2 gene (14). The present results indicate that the hormone receptor-binding element is absent, and that transcriptional activity was abolished by the POU element mutant, so that the transcriptional control of $S O X 2$ by NONO is via the latter POU element-mediated pathway. 

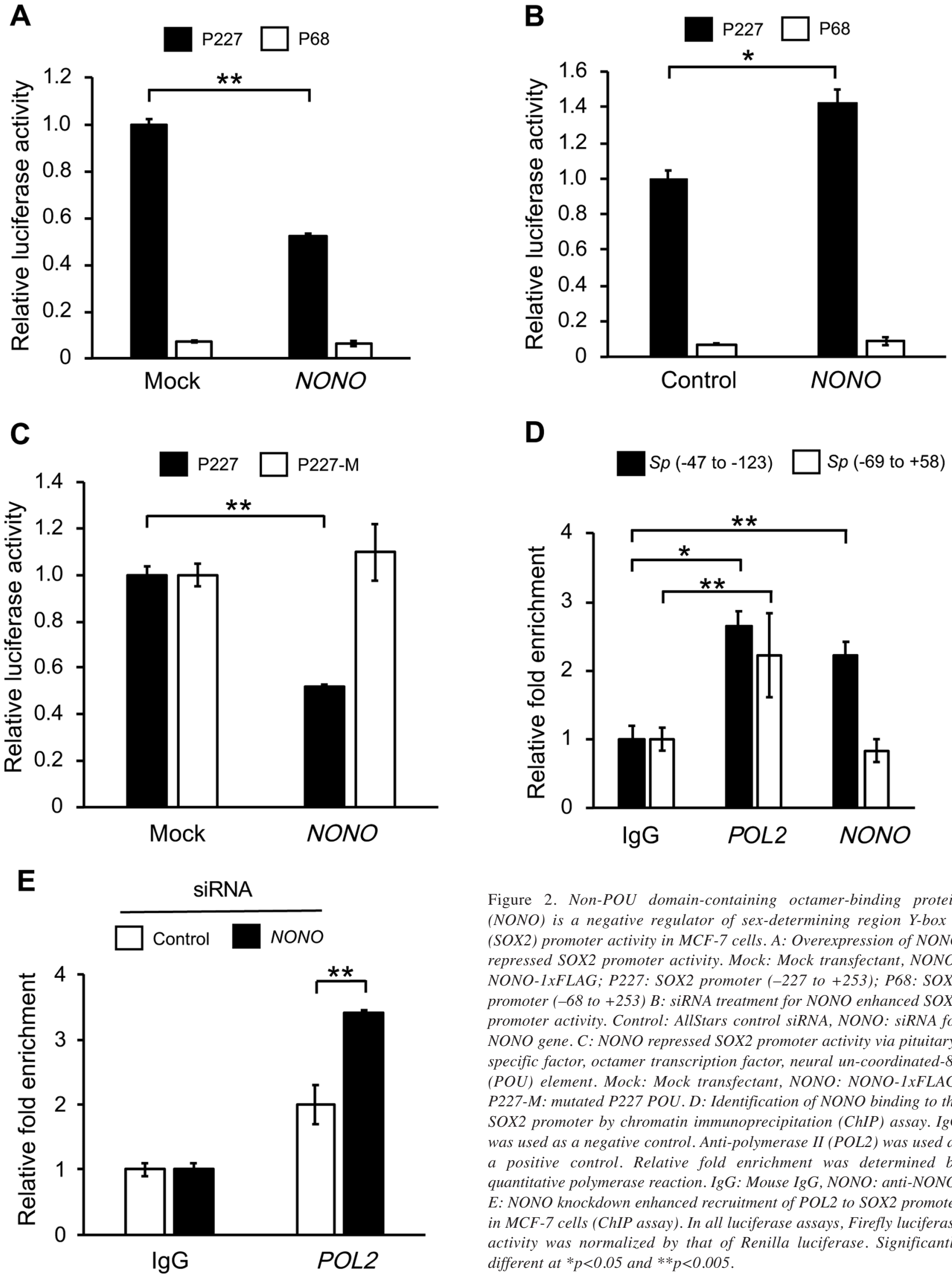

Figure 2. Non-POU domain-containing octamer-binding protein (NONO) is a negative regulator of sex-determining region Y-box 2 (SOX2) promoter activity in MCF-7 cells. A: Overexpression of NONO repressed SOX2 promoter activity. Mock: Mock transfectant, NONO: NONO-1xFLAG; P227: SOX2 promoter $(-227$ to +253$)$; P68: SOX2 promoter (-68 to +253) B: siRNA treatment for NONO enhanced SOX2 promoter activity. Control: AllStars control siRNA, NONO: siRNA for NONO gene. C: NONO repressed SOX2 promoter activity via pituitaryspecific factor, octamer transcription factor, neural un-coordinated-86 (POU) element. Mock: Mock transfectant, NONO: NONO-1xFLAG, P227-M: mutated P227 POU. D: Identification of NONO binding to the SOX2 promoter by chromatin immunoprecipitation (ChIP) assay. IgG was used as a negative control. Anti-polymerase II (POL2) was used as a positive control. Relative fold enrichment was determined by quantitative polymerase reaction. $\operatorname{Ig} G$ : Mouse $\operatorname{Ig} G$, NONO: anti-NONO. E: NONO knockdown enhanced recruitment of POL2 to SOX2 promoter in MCF-7 cells (ChIP assay). In all luciferase assays, Firefly luciferase activity was normalized by that of Renilla luciferase. Significantly different at $* p<0.05$ and $* * p<0.005$. 


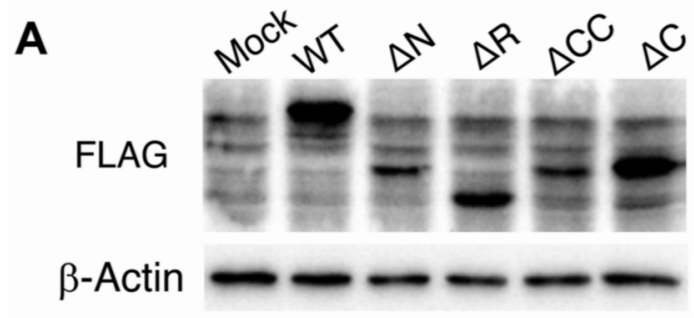

B

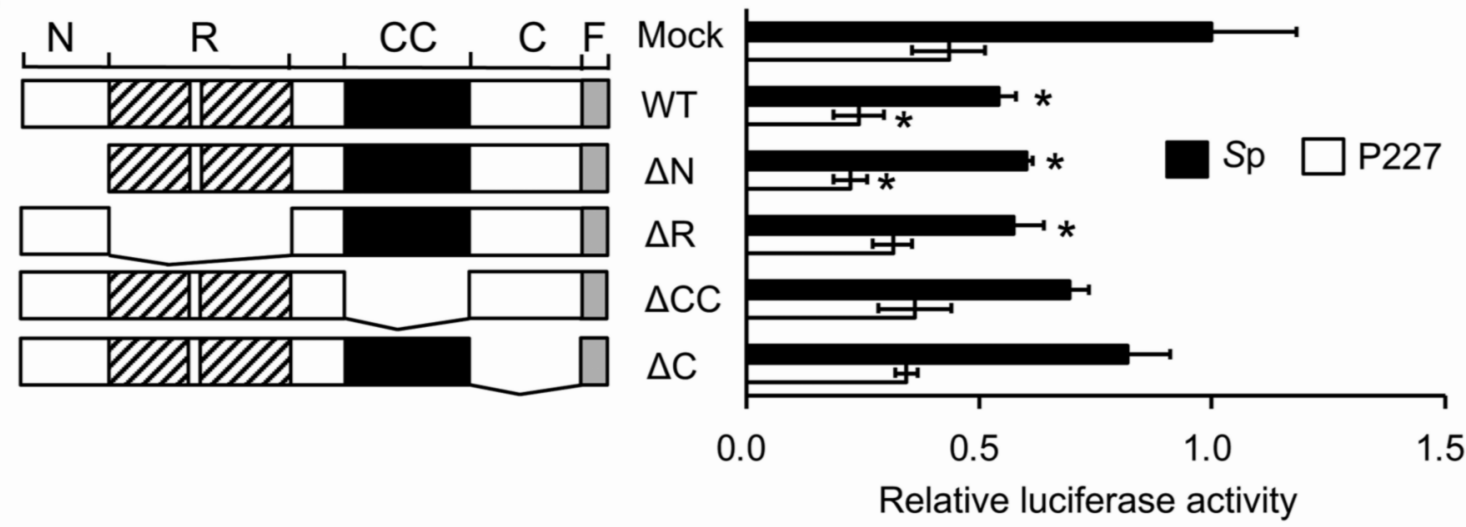

Figure 3. Identification of the region of non-POU domain-containing octamer-binding protein (NONO) that is responsible for sex-determining region Y-box 2 (SOX2) promoter repression by use of deletion mutants. A: Expression of NONO-deletion mutants in a breast cancer cell line. These products were confirmed by western blotting using anti-FLAG antibody. Deletions of: $\triangle N$ : N-Terminal region, $\triangle R$ : RNA binding domain, $\triangle C C$ : coiled-coil domain, $\triangle C$ : C-Terminal region. WT: full length of wild-type protein. B: Deletion mutants of NONO (left panel) and their corresponding luciferase activity (right panel). Sp: SOX2 promoter (-789 to +253$)$, P227: SOX2 promoter $(-227$ to +253$)$, Firefly luciferase activity was normalized by that of Renilla luciferase. Significantly different at $* p<0.05$.

NONO is an important factor for cell differentiation from stem cells. In mouse embryonic stem cells lacking Nono gene, differentiation is suppressed, and undifferentiated cells proliferate (23). In retinal epithelial cells that are important for the blood-retinal barrier, NONO plays an important role in inducing differentiation (24). NONO is highly expressed in various tumor cells and $C$-terminal deletions are frequently observed in tumor cells (25). Sphere-forming activity is a marker for cancer cell stemness (2). Our findings are consistent with these reports that wild-type NONO suppresses the expression of SOX2, an essential factor in stem cells. There were few reports on repressors of SOX2 transcription.

The interaction between epithelial-mesenchymal transition and mesenchymal-epithelial transition was reported to explain the plasticity of CSCs (4). Negative regulators of stem cellrelated factors appear to be other players involved in the plasticity of CSCs. Our findings suggest that NONO regulates SOX2 expression in human breast cancer cells using reduction of promoter activity.

\section{Conflicts of Interest}

The Authors declare no conflicts of interest.

\section{Authors' Contributions}

Designed research: S.L., J.H., and H.I.; performed research: S.L., H.T., and Y.K.; validation and formal analysis: T. H., Y.H., R.W., and S.H.; wrote the article: S.L., J.H., and H.I.

\section{Acknowledgements}

The Authors thank Sayuri Hamada and Shiori Ueno for their support.

\section{References}

1 Grimm D, Bauer J, Wise P, Krüger M, Simonsen U, Wehland M, Infanger M and Corydon TJ: The role of SOX family members in solid tumours and metastasis. Semin Cancer Biol pii: S1044579X (18), 30141-X, 2019. PMID: 30914279. DOI: 10.1016/j.semcancer.2019.03.004

2 Lengerke C, Fehm T, Kurth R, Neubauer H, Scheble V, Müller F, Schneider F, Petersen K, Wallwiener D, Kanz L, Fend F, Perner S, Bareiss PM and Staebler A: Expression of the embryonic stem cell marker SOX2 in early-stage breast carcinoma. BMC Cancer 11: 42, 2011. PMID: 21276239. DOI: 10.1186/1471-2407-11-42

3 Leis O, Eguiara A, Lopez-Arribillaga E, Alberdi MJ, HernandezGarcia S, Elorriaga K, Pandiella A, Rezola R and Martin AG: 
A

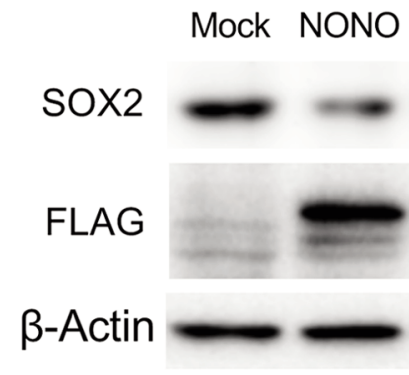

B

$$
\frac{\text { siRNA }}{\text { Control NONO }}
$$
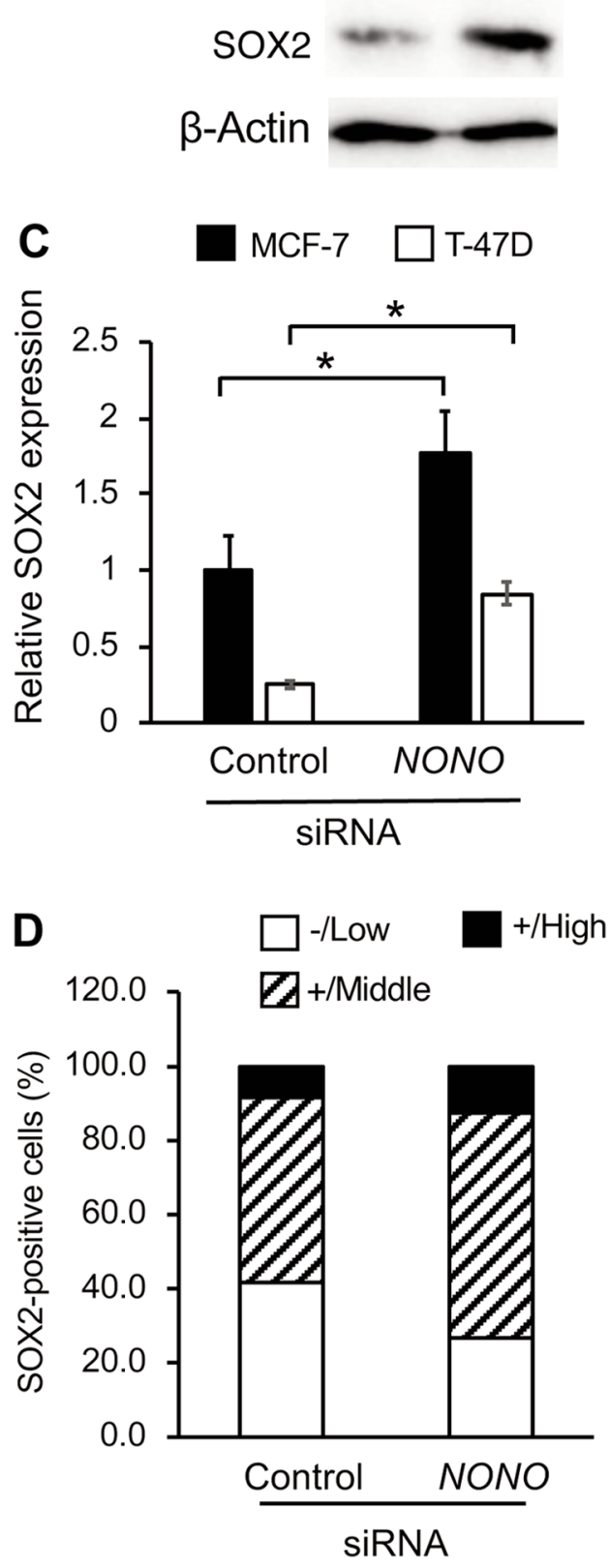

E
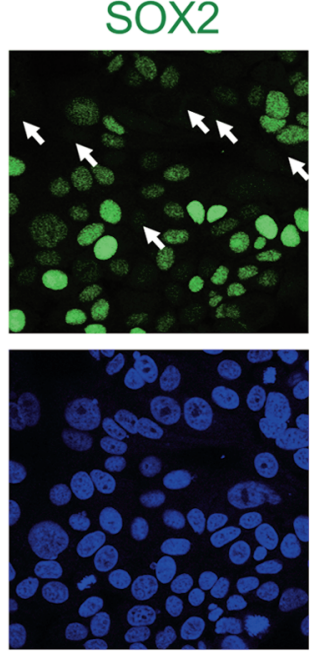

DAPI
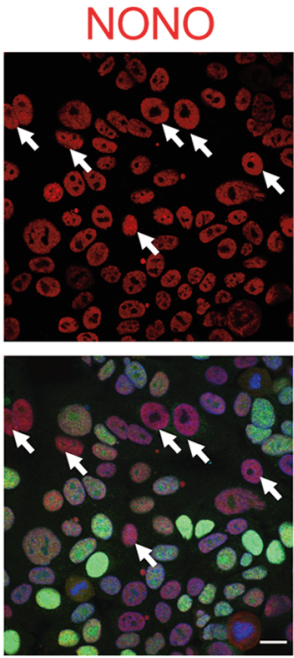

Merged

$\mathbf{F}$

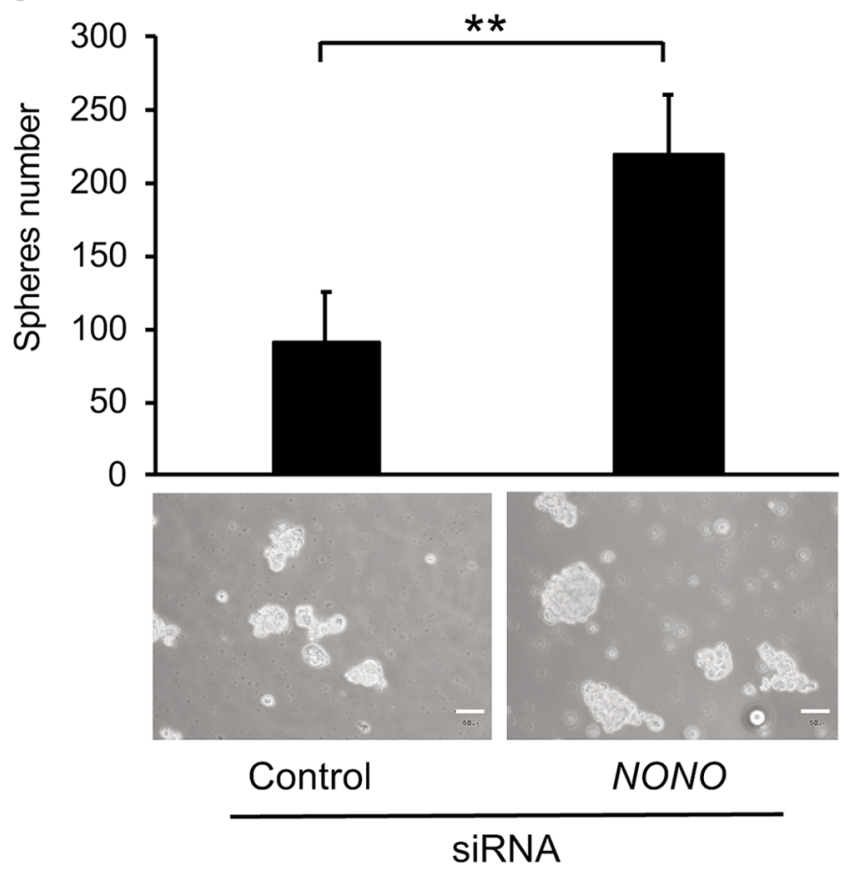

Figure 4. Non-POU domain-containing octamer-binding protein (NONO) repressed sex-determining region Y-box 2 (SOX2) expression and enhanced sphere formation in breast cancer cell line. A: Overexpression of NONO repressed protein expression of SOX2 in MCF-7 cells. Mock: Mock transfectant, NONO: NONO-1xFLAG. B: siRNA treatment to silence NONO enhanced the protein expression of SOX2 in MCF-7 cells. Control: AllStars control siRNA. C: Silencing of NONO enhanced SOX2 mRNA expression. Control: AllStars control siRNA, NONO: siRNA for NONO. $\beta$ Actin was used as an internal control. D: SOX2 protein-positive populations in NONO siRNA-treated MCF-7 cells. The SOX2-positive population was classified into three populations -/Low, +/Middle, and $+/$ High according to the fluorescence intensity. Control: AllStars control siRNA. E: Immunostaining for NONO and SOX2 protein in the MCF-7 breast cancer cell line. Arrows: NONO-positive cells; DAPI: 4',6diamidino-2-phenylindole. Bar: $50 \mu \mathrm{m}$. F: siRNA for NONO enhanced sphere formation in MCF-7 cell line. *Significantly different at $p<0.05$. 
SOX2 expression in breast tumours and activation in breast cancer stem cells. Oncogene 31(11): 1354-1365, 2012. PMID: 21822303. DOI: $10.1038 /$ onc. 2011.338

4 da Silva-Diz V, Lorenzo-Sanz L, Bernat-Peguera A, LopezCerda M and Muñoz P: Cancer cell plasticity: Impact on tumor progression and therapy response. Semin Cancer Biol 53: 4858, 2018. PMID: 30130663. DOI: 10.1016/j.semcancer. 2018.08.009

5 Liang S, Furuhashi M, Nakane R, Nakazawa S, Goudarzi H, Hamada $\mathbf{J}$ and Iizasa $\mathrm{H}$ : Isolation and characterization of human breast cancer cells with SOX2 promoter activity. Biochem Biophys Res Commun 437(2): 205-211, 2013. PMID: 2396710. DOI: $10.1016 /$ j.bbrc.2013.06.038

6 Jung K, Gupta N, Wang P, Lewis JT, Gopal K, Wu F, Ye X, Alshareef A, Abdulkarim BS, Douglas DN, Kneteman NM and Lai R: Triple-negative breast cancers comprise a highly tumorigenic cell subpopulation detectable by its high responsiveness to a SOX2 regulatory region 2 (SRR2) reporter. Oncotarget 6(12): 10366-10373, 2015. PMID: 25868977. DOI: 10.18632/oncotarget. 3590

7 Yang WT, Zhao ZX, Li B and Zheng PS: NF-YA transcriptionally activates the expression of SOX2 in cervical cancer stem cells. PLoS One 14(7): e0215494, 2019. PMID: 31365524. DOI: 10.1371/journal.pone.0215494

8 Li J, Li Z, Wu Y, Wang Y, Wang D, Zhang W, Yuan H, Ye J, Song X, Yang J, Jiang H and Cheng J: The Hippo effector TAZ promotes cancer stemness by transcriptional activation of SOX2 in head neck squamous cell carcinoma. Cell Death Dis 10(8): 603, 2019. PMID: 31399556. DOI: 10.1038/s41419-019-1838-0

9 Jia Y, Gu D, Wan J, Yu B, Zhang X, Chiorean EG, Wang Y and Xie J: The role of GLI-SOX2 signaling axis for gemcitabine resistance in pancreatic cancer. Oncogene 38(10): 1764-1777, 2019. PMID: 30382189. DOI: 10.1038/s41388-018-0553-0

10 Shav-Tal Y and Zipori D: PSF and P54(NRB)/NONO--multifunctional nuclear proteins. FEBS Lett 531(2): 109-114, 2002. PMID: 12417296. DOI: 10.1016/s0014-5793(02)03447-6

11 Hata K, Nishimura R, Muramatsu S, Matsuda A, Matsubara T, Amano K, Ikeda F, Harley VR and Yoneda T: Paraspeckle protein P54NRB links SOX9-mediated transcription with RNA processing during chondrogenesis in mice. J Clin Invest 118(9): 3098-3108, 2008. PMID: 18677406. DOI: 10.1172/JCI31373

12 Zhu Z, Zhao X, Zhao L, Yang H, Liu L, Li J, Wu J, Yang F, Huang $G$ and Liu J: P54(NRB)/NONO regulates lipid metabolism and breast cancer growth through SREBP-1A: Oncogene 35(11): 1399-1410, 2016. PMID: 26148231. DOI: 10.1038/onc. 2015.197

13 Dong X, Yu C, Shynlova O, Challis JR, Rennie PS and Lye SJ: $\mathrm{P} 54 \mathrm{NRB}$ is a transcriptional corepressor of the progesterone receptor that modulates transcription of the labor-associated gene, connexin 43 (GJA1). Mol Endocrinol 23(8): 1147-1160, 2009. PMID: 26148231. DOI: 10.1210/me.2008-0357

14 Yang X, Lin L, Zhang X, Ji Y, Lv J, Zhu Y, Yin Y, Sun Y and Han $X$ : Identification of a novel repressor element in the cyclooxygenase- 2 promoter and its nuclear binding protein. Clin Exp Pharmacol Physiol 35(10): 1204-1128, 2008. PMID: 18518878. DOI: $10.1111 / \mathrm{j} .1440-1681.2008 .04980 . x$

15 Pavao M, Huang YH, Hafer LJ, Moreland RB and Traish AM: Immunodetection of NMT55/P54NRB isoforms in human breast cancer. BMC Cancer 1: 15, 2001. PMID: 11710964. DOI:10.1186/1471-2407-1-15
16 Sasaki YT, Ideue T, Sano M, Mituyama $\mathrm{T}$ and Hirose $\mathrm{T}$ : MENepsilon/beta noncoding RNAs are essential for structural integrity of nuclear paraspeckles. Proc Natl Acad Sci USA 106(8): 2525-2530, 2009. PMID: 19188602. DOI: 10.1073/ pnas.0807899106

17 Hirose T, Shu MD and Steitz JA: Splicing of U12-type introns deposits an exon junction complex competent to induce nonsense-mediated mRNA decay. Proc Natl Acad Sci USA 101(52): 17976-17981, 2004. PMID: 15608055. DOI: 10.1073/pnas.0408435102

18 Passon DM, Lee M, Rackham O, Stanley WA, Sadowska A, Filipovska A, Fox AH and Bond CS: Structure of the heterodimer of human NONO and paraspeckle protein component 1 and analysis of its role in subnuclear body formation. Proc Natl Acad Sci USA 109(13): 4846-4850, 2012. PMID: 22416126. DOI: 10.1073/pnas.1120792109

19 Yang YS, Hanke JH, Carayannopoulos L, Craft CM, Capra JD and Tucker PW: NONO, a non-POU-domain-containing, octamer-binding protein, is the mammalian homolog of Drosophila nonAdiss. Mol Cell Biol 13(9): 5593-5603, 1933. PMID: 8355702. DOI:10.1128/mcb.13.9.5593

20 Mathur M, Tucker PW and Samuels HH: PSF is a novel corepressor that mediates its effect through $\operatorname{Sin} 3 \mathrm{~A}$ and the DNA binding domain of nuclear hormone receptors. Mol Cell Biol 21(7): 2298-2311, 2001. PMID: 11259580. DOI:10.1128/MCB.21.7.2298-2311.2001

21 Jacobsen BM and Horwitz KB: Progesterone receptors, their isoforms and progesterone regulated transcription. Mol Cell Endocrinol 357(1-2): 18-29, 2012. PMID: 21952082. DOI: 10.1016/j.mce.2011.09.016

22 Pham DH, Tan CC, Homan CC, Kolc KL, Corbett MA, McAninch D, Fox AH, Thomas PQ, Kumar R and Gecz J: Protocadherin 19 (PCDH19) interacts with paraspeckle protein NONO to co-regulate gene expression with estrogen receptor alpha (ER $\alpha$ ). Hum Mol Genet 26(11): 2042-2052, 2017. PMID: 28334947. DOI: $10.1093 / \mathrm{hmg} / \mathrm{ddx} 094$

23 Ma C, Karwacki-Neisius V, Tang H, Li W, Shi Z, Hu H, Xu W, Wang Z, Kong L, Lv R, Fan Z, Zhou W, Yang P, Wu F, Diao J, Tan L, Shi YG, Lan F and Shi Y: NONO, a bivalent domain factor, regulates ERK signaling and mouse embryonic stem cell pluripotency. Cell Rep 17(4): 997-1007, 2016. PMID: 27760330. DOI: $10.1016 /$ j.celrep.2016.09.078

24 Keil JM, Liu X and Antonetti DA: Glucocorticoid induction of occludin expression and endothelial barrier requires transcription factor p54 NONO. Invest Ophthalmol Vis Sci 54(6): 4007-4015, 2013. PMID: 23640037. DOI: 10.1167/iovs.13-11980

25 Alfano L, Caporaso A, Altieri A, Costa C, Forte IM, Iannuzzi CA, Barone D, Esposito L, Giordano A and Pentimalli F: NONO ubiquitination is mediated by FBW7 and GSK3 $\beta$ via a degron lost upon chromosomal rearrangement in cancer. J Cell Physiol 233(5): 4338-4344, 2018. PMID: 29150959. DOI: 10.1002/jcp.26269

Received March 25, 2020

Revised April 28, 2020

Accepted April 29, 2020 